\title{
PEMBERIAN HAK WARIS BAGI ANAK PEREMPUAN DI BALI DALAM PERSPEKTIF KEADILAN
}

\author{
Oleh: \\ I Nengah Ardika ${ }^{1}$
}

\begin{abstract}
Law of inheritance under Balinese customary law has made daughters as heirs. This is a fundamental change in view of Balinese customary law is more concerned with the male lineage. In this study addressed two issues namely 1) What is the basic consideration of granting inheritance rights for girls in Bali? 2) Does the inheritance under customary law Bali already reflect justice?. This study uses normative legal research, that examines the conflict of norms between Decision The Assembly General MUDP Bali No. 01 / KEP / PSM-3 / MDP Bali / X/2010, Decision of Supremen Court regarding heirs of men and women in customary law system similarly, patriarchy. Legal materials collected through library research. The analysis is conducted qualitatively. Philosophically, granting inheritance rights to daughters in Bali reflects substantive justice. Legally granting inheritance rights in accordance reflect gender equality. Sociologically, the equality between men and women is in conformity with the times. Inheritance under customary law Bali already reflect justice. The Assembly decision MUDP Bali Agung No. 01 / KEP / PSM-3 / MDP Bali / X/ 2010 is a product of gender responsive laws.
\end{abstract}

Keywords: daughters, inheritance right, Balinese customary law and justice.

\begin{abstract}
Abstrak
Hukum waris menurut hukum adat Bali telah membuat anak perempuan sebagai ahli waris. Hal ini adalah perubahan mendasar dalam hukum adat Bali yang lebih memperhatikan garis keturunan laki-laki. Dalam penelitian ini dibahas dua permasalahan yaitu 1) Bagaimanakah dasar pertimbangan pemberian hak waris bagi anak perempuan di Bali? dan 2) Apakah pembagian warisan menurut hukum adat Bali sudah mencerminkan keadilan? Penelitian ini merupakan penelitian hukum normatif, yang meneliti mengenai konflik norma antara Keputusan Majelis Umum MUDP Bali Nomor 01 / KEP / PSM-3 / MDP Bali / X / 2010, Keputusan Pengadilan tentang ahli waris laki-laki dan perempuan dalam hukum adat sistem patriarki. Bahan hukum dikumpulkan melalui studi kepustakaan. Analisis dilakukan secara kualitatif. Secara filosofis, pemberian hak waris untuk anak perempuan di Bali mencerminkan keadilan substantif. Secara hukum, pemberian hak waris mencerminkan kesetaraan gender. Secara sosiologis, kesetaraan antara laki-laki dan perempuan sudah sesuai dengan perkembangan zaman. Warisan menurut hukum adat Bali sudah mencerminkan keadilan. Keputusan Majelis MUDP Bali Agung Nomor 01 / KEP / PSM-3 / MDP Bali / X / 2010 adalah produk gender hukum responsif.
\end{abstract}

Kata kunci: anak perempuan, hak waris, hukum adat Bali dan keadilan.

1 Penulis adalah jaksa dari kejaksaan negeri buol sulawesi tengah, Email: ardi-kadek82@gmail.com 


\section{PENDAHULUAN}

Hukum waris merupakan bagian dalam lapangan hukum privat yang menunjukkan aneka warna hukum di Indonesia. Hukum adat waris di Indonesia berada pada alam pikiran tradisional yang bersendi atas prinsipprinsip yang timbul dari aliran-aliran pikiran komunal. Pembagian warisan didasarkan pada ketentuan hukum adat yang berbeda di masing-masing daerah.

Pada dasarnya pembagian warisan didasarkan pada hukum adat, namun dalam perkembangannya, apabila terjadi permasalahan maka ahli waris akan menyelesaikannya melalui lembaga pengadilan. Hal ini dapat dilihat pada Putusan Mahkamah Agung tanggal 23 Oktober 1961, No.179/K/SIP/1961 yang memutuskan anak laki-laki maupun anak perempuan di tanah Karo berhak atas warisan orang tua dalam arti bagian anak lakilaki sama dengan anak perempuan. Putusan hakim yang juga menentukan ahli waris adalah Putusan Mahkamah Agung tanggal 3 Desember 1958, Nomor 200 K/SIP/1958. Dalam putusan tersebut dinyatakan bahwa menurut hukum Adat Bali yang berhak mewaris hanyalah keturunan pria dan pihak keluarga pria dan anak angkat lelaki.

Putusan hakim yang berbeda mengenai ahli waris di Batak Karo dan Bali yang menganut sistem patrilineal menimbulkan dua kemungkinan yakni keadilan dan bias gender. John Jay menyatakan justice is indiscriminately due to all, without regard to numbers, wealth, or rank. ${ }^{2}$ Keadilan pada dasarnya tanpa diskriminasi kepada semua orang, tanpa memperhatikan tingkatan, kekayaan dan peringkat. Putusanhakimjugadapatmenimbulkan bias gender. Mengenai bias gender oleh hakim, Hari Chand menyatakan:

Since judges as well as other law officers have their biases against women, their decisions are most influenced by their biases. Four elements have been pinpointed by feminists, the legal framework, legal literacy, access to the court and fair treatment in the courts as necessary in order to avoid exclusion of women from justice. ${ }^{3}$

Kedua putusan yang berbeda dalam sistem patriarki tentu didasarkan pada pertimbangan yang berbeda pula. Dalam perkembangannya, hak waris bagi anak perempuan mulai diperhatikan dalam masyarakat adat di Bali. Pada tahun 2010 melalui Keputusan Pesamuhan Agung MUDP Bali Nomor 01/KEP/PSM-3/MDP Bali/X/2010, anak perempuan yang ninggal kadaton terbatas diberikan hak waris. Oleh sebab itu sangat menarik untuk membahas mengenai "Pemberian Hak Waris Bagi Anak

2 Achmad Ali, 2009, Menguak Teori Hukum (Legal Theory dan Teori Peradilan (Judicialprudence) Termasuk Intepretasi Undang-undang (Legisprudence), Kencana, Jakarta, hlm. 221.

3 Hari Chand, 1994, Modern Jurisprudence, International Law Book Services, Kuala Lumpur, hlm. 335. 
Perempuan di Bali Dalam Perspektif Keadilan."

Berdasarkan latar belakang yang telah diuraikan sebelumnya, maka dapat dirumuskan permasalahan sebagai berikut:

a. Bagaimanakah dasar pertimbangan pemberian hak waris bagi anak perempuan di Bali?

b. Apakah pembagian warisan menurut hukum adat Bali sudah mencerminkan keadilan?

Originalitas penelitian dilakukan dengan membandingkan beberapa penelitian lain, diantaranya:

1. Kedudukan Hak Mewaris Wanita Hindu dalam Sistem Hukum Adat Waris di Bali yang ditulis oleh Ni Luh Gede Isa Prareti pada Jurnal Hukum Universitas Brawijaya, Malang. Dalam penelitian ini diuraikan mengenai kesesuaian mengenai ketentuan tidak memberikan hak mewaris bagi anak perempuan dengan perkembangan masyarakat hukum adat Bali dan tindakan yang dilakukan agar anak perempuan di Bali mendapatkan hak mewaris. Dalam penelitian tersebut, fokus penelitian adalah inferioritas anak perempuan dalam hak mewaris ${ }^{4}$ sedangkan dalam penelitian ini justru membahas pemberian hak waris bagi anak perempuan di Bali.

$4 \quad$ Ni Luh Gede Isa Prareti, 2015, Kedudukan Hak Mewaris Wanita Hindu dalam Sistem Hukum Adat Waris di Bali, Jurnal Hukum Universitas Brawijaya, Malang.
2. Hak Waris Anak Perempuan dalam Hukum Waris Adat Bali yang ditulis oleh I Gede Dharman Gunawan, pada Jurnal Satya Dharma, STAHN Tampung Penyang, Palangkaraya. Dalam penelitian Penelitian ini mengkaji mengenai kelemahan posisi perempuan dalam memperoleh hak waris menurut hukum adat Bali, ${ }^{5}$ sedangkan penelitian ini mengkaji mengenai analisis keadilan dalam dasar pertimbangan pemberian hak waris bagi anak perempuan di Bali.

3. Mengikis Ketidakadilan Gender dalam Adat Bali, yang ditulis oleh Ni Ketut Sri Utari. Dalam penelitian tersebut dibahas mengenai hukum waris dalam hukum adat Bali yang bias gender dan perlunya rekonstruksi sosial untuk mewujudkan keadilan gender dalam hukum waris di Bali, ${ }^{6}$ sedangkandalampenelitian ini dibahas mengenai hak waris bagi perempuan itu sendiri sesuai dengan perkembangan Keputusan Pesamuhan Agung MUDP Bali Nomor 01/KEP/ PSM-3/MDP Bali/X/2010 dan

$5 \quad$ I Gede Dharman Gunawan, 2015, Hak Waris Anak Perempuan dalam Hukum Waris Adat Bali, Jurnal Satya Dharma, STAHN Tampung Penyang, Palangkaraya.

6 Ketut Sri Utari, 2006, Mengikis Ketidakadilan Gender dalam Adat Bali, disampaikan pada Temu Ilmiah II Asosiasi Pengajar dan Peminat Hukum Berspektif Gender se Indonesia (APPHGI), pada 18-20 September 2006, di Surabaya. 
membandingkannya dengan berbagai yurisprudensi.

Tujuan penelitian ini terdiri dari tujuan umum dan tujuan khusus. Pertama Tujuan umum dalam penelitian ini adalah untuk menganalisis pemberian hak waris bagi anak perempuan di Bali dalam perspektif keadilan.

Tujuan khusus dalam penelitian ini adalah:

a. Untuk menganalisis dasar pertimbangan pemberian hak waris bagi anak perempuan di Bali.

b. Untuk menganalisis pembagian warisan menurut hukum adat Bali sudah mencerminkan keadilan.

\section{METODE PENELITIAN}

Penelitian ini menggunakan pendekatan yuridis normatif yang mengkaji mengenai konflik norma antara Keputusan Pesamuhan Agung MUDP Bali Nomor 01/KEP/PSM3/MDP Bali/X/2010, Putusan MA mengenai ahli waris laki-laki dan perempuan pada sistem hukum adat yang sama yakni patriarkhi.

Jenis pendekatan yang digunakan adalah pendekatan perundangundangan (the statute approach) dengan mengkaji peraturan perundangundangan dan yurispubdensi. Pendekatan konsep hukum (analitical and conseptual approach) juga digunakan dalam menguraikan variable mengenai hukum waris, perempuan dan keadilan.
Bahan hukum berasal dari bahan hukum primer yakni Keputusan Pesamuhan Agung MUDP Bali Nomor 01/KEP/PSM-3/MDP Bali/X/2010, Putusan Mahkamah Agung tanggal 23 Oktober 1961, No.179/K/SIP/1961, Putusan Mahkamah Agung tanggal 3 Desember 1958, Nomor $200 \mathrm{~K} /$ SIP/1958 dan instrumen hukum terkait. Bahan hukum sekunder diperoleh dari literatur-literatur yang relevan dengan pembahasan.

Pengumpulan bahan hukum yang digunakan dalam penelitian ini adalah melalui teknik studi kepustakaan. Dokumen dan literatur hukum dikumpulkan dan dirujuk sebagai bahan dalam penelitian.

Analisis bahan hukum dilakukan secara kualitatif dengan menjelaskan mengenai kajian hukum adat Bali khususnya mengenai kewarisan bagi perempuan dalam perspektif keadilan. Hasil penelitian diuraikan secara deskriptif analitis.

\section{PEMBAHASAN}

\subsection{Dasar Pertimbangan Pembe-} rian Hak Waris Bagi Anak Perempuan di Bali

Masalah pewarisan seringkali menimbulkan persoalan. Waris merujuk pada hak dan kewajiban terhadap harta kekayaan dari seseorang pada waktu ia meninggal dunia akan beralih kepada orang lain yang masih hidup. Pengaturan masalah waris di Indonesia berada pada lapangan hukum perdata, oleh sebab itu, ketentuan 
hukum waris tunduk pada hukum adat, hukum perdata (BW) atau hukum yang dipilih.

Pembagian warisan di Bali disesuaikan dengan sistem kekerabatan masyarakat Bali yang menganut sistem purusha. Pada mulanya, yang berhak mendapatkan warisan di Bali hanyalah keturunan pria dari keluarga pihak pria dan anak angkat laki-laki sebagaimana yang diperkuat dalam Putusan MA tanggal 3 Desember 1958, Nomor 200 K/SIP/1958. Secara filosofis, Putusan MA tanggal 3 Desember 1958, Nomor 200 K/SIP/1958 menganut teori keadilan partikular (Particular justice) dimana keadilan dipandang dari sisi budaya. Putusan ini dikatakan oleh masyarakat Bali karena sesuai dengan hukum adatnya, namun belum tentu adil bagi masyarakat lain.

Putusan MA tanggal 3 Desember 1958, Nomor $200 \mathrm{~K} / \mathrm{SIP} / 1958$ juga mendasarkan pada teori HAM yakni teori relativisme budaya (cultural relativism theory). Gagasan tentang relativisme budaya memandang bahwa satu-satunya sumber keabsahan hak dan kaidah moral adalah kebudayaan. Menurut gagasan ini, hak asasi manusia dianggap akan dipahami menurut konteks kebudayaan di masingmasing negara. ${ }^{7}$ Hak asasi manusia dipandang sebagai interaksi sosiokultural, dengan demikian pandangan mengenai kemanusiaan bukanlah hal

7 Rhona K.M. Smith et.al., 2010, Hukum Hak Asasi Manusia, Pusat Studi Hak Asasi Universitas Islam Indonesia (PUSHAM UII), Yogyakarta, hlm. 20 yang universal, namun sesuai dengan tradisi masing-masing bangsa. ${ }^{8}$

Secara yuridis, Putusan MA tanggal 3 Desember 1958, Nomor $200 \mathrm{~K} / \mathrm{SIP} / 1958$ sejalan dengan hukum adat Bali yang menarik garis keturunan pada garis purusa yang secara umum adalah laki-laki. Dalam pandangan tradisional yang masih kuat mendominasi alam pikiran masyarakat Bali, pewaris adalah seorang ayah (laki-laki). Dalam logika ini, harta warisan diturunkan melali garis lakilaki sehingga semua harta adalah milik laki-laki, sedangkan perempuan bukanlah pemilik harta. Dalam hukum adat Bali yang berdasarkan pada sistem kekeluargaan kepurusa, orangorang yang dapat diperhitungkan sebagai ahli waris dalam garis pokok keutamaan dan garis pokok pengganti adalah para laki-laki dalam keluarga bersangkutan, sepanjang tidak putus haknya sebagai ahli waris. ${ }^{9}$

Secara sosiologis, Putusan MA tanggal 3 Desember 1958, Nomor 200 K/SIP/1958 tidak dapat dipisahkan dengan nilai-nilai dalam masyarakat Bali. Hukum waris adat sangat erat hubungannya dengan sifatsifat kekeluargaan dari masyarakat hukum yang bersangkutan beserta

8 IDewa Gede Atmadja, 2010, Hukum Konstitusi Problematika Konstitusi Indonesia Sesudah Perubahan UUD 1945, Setara, Malang, hlm 207-208, (selanjutnya disebut I Dewa Gede Atmadja I).

9 Wayan P. Windia dan Ketut Sudantra, 2006, Pengantar Hukum Adat Bali, Lembaga Dokumentai dan Publikasi Fakultas Hukum Universitas Udayana, Denpasar, hlm. 117118. 
pengaruhnya pada harta kekayaan yang ditinggalkan dan berada pada masyarakat itu. Di samping itu, hukum waris adat tidak hanya mendapat pengaruh dari perubahan-perubahan sosial, tetapi juga dari peraturanperaturan hukum asing sejenis yang oleh para hakim selalu diterapkan in concreto walaupun pengaruhnya sangat kecil. ${ }^{10}$

Hukum dan nilai-nilai sosial budaya masyarakat itu ternyata berkaitan erat dimana hukum yang baik tidak lain adalah hukum yang mencerminkan nilai-nilai yang hidup dalam masyarakat. ${ }^{11}$ Kehidupan masyarakat Bali yang menempatkan kewajiban bagi anak laki-laki (kecuali dalam status perkawinan nyentana) menjadi dasar pertimbangan bahwa ahli waris hanyalah anak laki-laki saja.

Perkembangan sistem pewarisan dalam hukum adat Bali mengikuti perkembangan zaman dimana hukum waris dalam hukum adat Bali kini telah memberikan tempat bagi anak perempuan. Dalam Keputusan Pesamuhan Agung MUDP Bali Nomor 01/KEP/PSM-3/MDP Bali/X/2010, tanggal 15 Oktober 2010 memberikan hak waris bagi anak perempuan yang ninggal kadaton terbatas. Mereka yang ninggal kedaton terbatas dimungkinkan mendapatkan harta

10 C. Dewi Wulansari, 2010, Hukum Adat Indonesia Suatu Pengantar, Refika Aditama, Bandung, hlm. 74.

11 Lili Rasdjidi dan Ira Thania Rasjidi, 2007, Dasar-dasar Filsafat dan Teori Hukum, Citra Aditya Bakti, Bandung, hlm. 80. warisan didasarkan atas asas ategen asuwun (dua berbanding satu), dengan saudaranya yang berstatus purusa. Ninggal kedaton terbatas yaitu ninggal kedaton tetapi dalam batas tertentu masih memungkinkan melaksanakan swadharma sebagai umat Hindu. ${ }^{12}$ Berdasarkan Keputusan tersebut, golongan ninggal kadaton terbatas adalah sebagai berikut.

1. Perempuan yang melangsungkan perkawinan biasa.

2. Laki-laki yang melangsungkan perkawinan nyentana/nyeburin.

3. Telah diangkat anak (kaperas sentana) oleh keluarga lain sesuai dengan agama Hindu dan hukum adat Bali.

4. Menyerahkan diri (makidihang raga) kepada keluarga lain atas kemauan sendiri.

Secara filosofis, Keputusan Pesamuhan Agung MUDP Bali Nomor 01/KEP/PSM-3/MDP Bali/X/2010 memberikan rasa keadilan kepada perempuan yang sebelum adanya keputusan tersebut dikesampingkan dalam pembagian warisan. Menurut Rawls didasarkan keadilan pada asasnya dimana setiap orang harus mempunyai hak atas kebebasan. ${ }^{13}$ Keputusan Pesamuhan Agung MUDP Bali Nomor 01/KEP/PSM-3/MDP

12 Wayan P. Windia, Ni Made Wiasti dan Ni Luh Arjani, 2012, Pewarisan Perempuan Menurut Hukum Adat di Bali, Udayana University Press, Denpasar, hlm. 80.

13 B. Arief Sidharta, Meuwissen 2008, Tentang Pengembanan Hukum, Ilmu Hukum, dan Filsafat Hukum, Refika Aditama, Bandung, hlm. 87. 
Bali/X/2010 didasarkan pada keadilan global (global justice). Persamaan antara laki-laki dan perempuan harus dilakukan pada semua aspek dalam kehidupan, bukan hanya dalam ruang lingkup kewajiban namun juga dalam ruang lingkup hak.

Persamaan hak dan kewajiban antara laki-laki dan perempuan dalam pewarisan merupakan cerminan dari penegakan HAM. HAM adalah hakhak yang diberikan langsung oleh Tuhan yang Maha Pencipta (hakhak yang bersifat kodrati). Pada hakikatnya, dua hak dasar yang paling fundamental dalam hak asasi manusia adalah hak persamaan dan hak kebebasan. ${ }^{14}$ Persamaan hak ini berakar dari teori universalis (universalist theory) hak asasi manusia. Dicermati dari pertimbangan bahwa kesetaraan hak antara laki-laki dan perempuan merupakan hukum yang hidup di seluruh Indonesia, maka keadilan yang dianut adalah keadilan substantif. Tolok ukur hukum adil, lebih mengutamakan doelmatigheid daripada rechtsmatigheid. ${ }^{15}$

Secara yuridis, dimasukkan perempuan sebagai ahli waris tidak lepas dari perjuangan hak asasimanusia dan pergerakan kaum perempuan yang terlegitimasi dalam instrumen hukum. Dalam Universal Declaration of Human Rights disebutkan: “...in

14 Zainuddin Ali, 2010, Filsafat Hukum, Sinar Grafika, Jakarta, hlm. 146.

15 I Dewa Gede Atmadja, 2013, Filsafat Hukum Dimensi Temati dan Historis, Setara, Malang, hlm. 85, (selanjutnya disebut I Dewa Gede Atmadja II). the equal rights of men and women..." Ketentuan tersebut diderivasi dalam Konvensi perempuan yang memiliki prinsip-prinsip persamaan substantive, yakni persamaan kesempatan, akses dan penikmatan manfaat, prinsip nondiskriminasi dan prinsip kewajiban negara. ${ }^{16}$

Secara sosiologis, persamaan kedudukan antara laki-laki dan perempuan sudah sesuai dengan perkembangan zaman. Kenyataannya banyak anak perempuan yang lebih bertanggungjawabkepadakeluarganya dari anak laki-laki meskipun anak perempuan tersebut sudah melangsungkan perkawinan. Ditinjau secara harafiah, kata "perempuan" berasal dari akar Bahasa Melayu yang berarti empu atau indik, artinya memberi hidup. ${ }^{17}$ Sebagai pemberi hidup sudah selayaknya perempuan memiliki kedudukan yang setara dengan laki-laki dalam hal mewaris.

\subsection{Pembagian Warisan Menurut Hukum Adat Bali yang Mencerminkan Keadilan}

Pada mulanya, yang dipandang sebagai ahli waris dalam masyarakat adat Bali adalah yang berstatus hukum purusa (pada umumnya adalah lakilaki) yakni sebagai penerus keturunan

16 Moerti Hadiati Soeroso, 2011, Kekerasan Dalam Rumah Tangga Dalam Perspektif Yuridis-Viktimologis, Sinar Grafika, Jakarta, hlm. 48.

17 Abdul Wahid dan Muhammad Irfan, 2001, Perlindungan Korban Kekerasan Seksual Advokasi atas Hak Asasi Perempuan, Refika Aditama, Bandung, hlm. 29. 
dalam kewajiban pemujaan pura leluhur (kawitan). Berdasarkan pertimbangan ini maka wajar bila Putusan MA tanggal 3 Desember 1958, Nomor $200 \mathrm{~K} / \mathrm{SIP} / 1958$ sejalan dengan hukum adat Bali, desa pakraman dan alam kehidupan masyarakat Bali.

Hukum harus mengikuti perkembangan masyarakat agar hukum tidak tertinggal. Putusan MA tanggal 3 Desember 1958, Nomor $200 \mathrm{~K} / \mathrm{SIP} / 1958$ tidak sesuai dengan keadilan dan perkembangan zaman saat ini. Putusan tersebut menimbulkan diskiminasi terhadap perempuan. DalamPutusanMA tanggal3 Desember 1958, Nomor 200 K/SIP/1958 terlihat bahwa hukum bersifat pallocentris. Bagi feminist legal theory, hukum dibangun dan dikonstruksikan dalam logika laki-laki. Akibatnya hukum telah menyumbang kepada penindasan terhadap perempuan. ${ }^{18}$

Sistem hukum dengan dominasi laki-laki ini menempatkan perempuan pada posisi subordinat. ${ }^{19}$ Budaya patriarki yang dipertahankan dalam Putusan MA tanggal 3 Desember 1958, Nomor 200 K/SIP/1958 menimbulkan subordinasi bagi perempuan. Keputusan Pesamuhan Agung MUDP BaliNomor01/KEP/PSM-3/MDPBali/ $\mathrm{X} / 2010$ yang memberikan hak waris bagi anak perempuan yang ninggal

18 Benard L. Tanya, Yoan N. Simanjuntak dan Markus Y. Hage, 2010, Teori Hukum Strategi Tertib Manusia Lintas Ruang dan Generasi, Genta, Yogyakarta, hlm. 179-180.

19 A. Muktie Fadjar, 2013, Teori-teori Hukum Kontemporer, Setara, Malang, hlm. 81. kedaton terbatas merupakan suatu terobosan hukum yang memberikan rasa keadilan. Keputusan MUDP ini mencerminkan sistem hukum yang responsive gender.

Dikeluarkannya Keputusan Pesamuhan Agung MUDP Bali Nomor 01/KEP/PSM-3/MDP Bali/ $\mathrm{X} / 2010$ menjamin kepastian hukum bagi keluarga untuk memberikan hak waris kepada anak perempuan sehingga terhindar dari konflik perebutan hak waris dari saudara laki-lakinya. Pasamuhan Agung III Majelis Utama Desa Pakraman Bali memutuskan mengenai kedudukan suami istri dan anak terhadap harta pusaka dan harta gunakaya dimana dinyatakan "Anak kandung (laki-laki atau perempuan) serta anak angkat (laki-laki atau perempuan) berhak atas harta gunakaya orangtuanya, sesudah dikurangi sepertiga sebagai duwe tengah (harta bersama), yang dikuasai (bukan dimiliki) oleh anak yang nguwubang (melanjutkan swadharma atau tanggung jawab) orangtuanya.

Hasil Pasamuhan Agung yang dituangkan dalam Keputusan Pesamuhan Agung MUDP Bali Nomor 01/KEP/PSM-3/MDP Bali/X/2010 ini menjadi simbol fungsi hukum sebagai alat pengubah masyarakat. Artinya hukum dapat berperan sebagai pemimpin perubahan dalam kehidupan masyarakat guna mewujudkan ketertiban pada masyarakat itu 
sendiri. ${ }^{20}$ Hukum yang baik adalah hukum yang sesuai dengan hukum yang hidup di dalam masyarakat saat ini.

Pemberian hak sebagai ahli waris bagi anak perempuan sesuai dengan ajaran agama Hindu yang sangat menghargai kaum perempuan. Dalam Manawadharmasastra Bab III Sloka 56 yang bunyinya "Yatra naryastu pujyante, Ramante tatra dewata, Yatraitastu na pujiante, Sarwastalah kriyah" (tempat dimana wanita dihormati, maka disanalah para dewa-dewa akan merasa senang, tetapi dimana wanita tidak dihormati, maka tidak ada upacara suci apapun yang berpahala).

Pemberian hak waris bagi anak perempuan dalam sistem kekerabatan patrilineal bukan hanya terjadi di Bali saja, namun juga pada masyarakat Batak Karo sebagaimana yang tercantum dalam Putusan MA tanggal 23 Oktober 1961, No.179/K/SIP/1961 mengenai pewarisan dalam masyarakat Batak Karo. Berdasarkan Putusan tersebut, maka ahli waris dalam sistem kekeluargaan masyarakat Batak Karo tidak hanya anak laki-laki namun juga anak perempuan.

Putusan MA tanggal 23 Oktober 1961, No.179/K/SIP/1961 dan Keputusan Pesamuhan Agung MUDP Bali Nomor 01/KEP/PSM-3/ MDP Bali/X/2010 dengan sendirinya mengukuhkan fungsi hukum sebagai

20 Soerjono Soekanto, 2009, Pokok-pokok Sosiologi Hukum, PT RajaGrafindo Persada, Jakarta, hlm. 43. alat pengubah masyarakat. Hukum sebagai alat pengubah masyarakat, artinya hukum dipergunakan sebagai suatu alat oleh agent of change. Kedua produk hukum tersebut memberikan keadilan gender bagi laki-laki maupun perempuan.

\section{KESIMPULAN}

a. Dasar pertimbangan pemberian hak waris bagi anak perempuan di Bali secara filosofis mencerminkan keadilan substantive. Secara yuridis pemberian hak waris sesuai dengan hak asasi manusia yang mengamatkan kesetaraan. Secara sosiologis, persamaan kedudukan antara laki-laki dan perempuan sudah sesuai dengan perkembangan zaman. Pemberian hak waris bagi anak perempuan di Bali bukan hanya dalam konteks pemberian hak, namun juga pembebanan kewajiban, sehingga anak perempuan yang berhak menjadi ahli waris hanyalah anak perempuan yang ninggal kedaton terbatas.

b. Pembagian warisan menurut hukum adat Bali sudah mencerminkan keadilan. Keputusan Pesamuhan Agung MUDP Bali Nomor 01/KEP/ PSM-3/MDP Bali/X/2010 merupakan produk hukum yang responsive gender dengan berlandaskan pada global justice, 
teori universalis, instrumen hukum yang menyatakan persamaan hak antara laki-laki dan perempuan serta perubahan zaman yang menginginkan kesetaraan gender. Pemberian hak sebagai ahli waris bagi anak perempuan sesuai dengan ajaran agama Hindu yang sangat menghargai kaum perempuan sebagaimana yang tertuang dalam Manawadharmasastra

\section{DAFTAR PUSTAKA}

Abdul Wahid dan Muhammad Irfan, 2001, Perlindungan Korban Kekerasan Seksual Advokasi atas Hak Asasi Perempuan, Refika Aditama, Bandung.

Achmad Ali, 2009, Menguak Teori Hukum (Legal Theory dan Teori Peradilan (Judicialprudence) Termasuk Intepretasi Undangundang (Legisprudence), Kencana, Jakarta.

Arief Sidharta, B. Meuwissen 2008, Tentang Pengembanan Hukum, IlmuHukum, dan FilsafatHukum, Refika Aditama, Bandung.

Atmadja, I Dewa Gede, 2010, Hukum Konstitusi Problematika Konstitusi Indonesia Sesudah Perubahan UUD 1945, Setara, Malang.

Atmadja, I Dewa Gede, 2013, Filsafat Hukum Dimensi Temati dan Historis, Setara, Malang.

Benard L. Tanya, Yoan N. Simanjuntak dan Markus Y. Hage, 2010, Teori
Hukum Strategi Tertib Manusia Lintas Ruang dan Generasi, Genta, Yogyakarta.

Chand, Hari, 1994, Modern Jurisprudence, International Law Book Services, Kuala Lumpur.

Dewi Wulansari, C.2010, Hukum Adat Indonesia Suatu Pengantar, Refika Aditama, Bandung.

Lili Rasdjidi dan Ira Thania Rasjidi, 2007, Dasar-dasar Filsafat dan Teori Hukum, Citra Aditya Bakti, Bandung.

Moerti Hadiati Soeroso, 2011, Kekerasan Dalam Rumah Tangga Dalam Perspektif Yuridis-Viktimologis, Sinar Grafika, Jakarta.

Muktie Fadjar, A., 2013, Teori-teori Hukum Kontemporer, Setara, Malang.

Rhona K.M. Smith et.al., 2010, Hukum Hak Asasi Manusia, Pusat Studi Hak Asasi Universitas Islam Indonesia (PUSHAM UII), Yogyakarta.

Soerjono Soekanto, 2009, Pokokpokok Sosiologi Hukum, PT RajaGrafindo Persada, Jakarta.

Windia, Wayan P. dan Ketut Sudantra, 2006, Pengantar Hukum Adat Bali, Lembaga Dokumentai dan Publikasi Fakultas Hukum Universitas Udayana, Denpasar.

Windia, Wayan P., Ni Made Wiasti dan Ni Luh Arjani, 2012, Pewarisan Perempuan Menurut Hukum Adat di Bali, Udayana University Press, Denpasar. 
Zainuddin Ali, 2010, Filsafat Hukum, Sinar Grafika, Jakarta.

Dharman Gunawan, I Gede, 2015, Hak

Waris Anak Perempuan dalam

Hukum Waris Adat Bali, Jurnal SatyaDharma, STAHNTampung Penyang, Palangkaraya.

Isa Prareti, Ni Luh Gede, 2015, Kedudukan HakMewaris Wanita Hindu dalam Sistem Hukum Adat Waris di Bali, Jurnal Hukum Universitas Brawijaya, Malang.

Sri Utari, Ketut, 2006, Mengikis Ketidakadilan Gender dalam Adat Bali, disampaikan pada Temu Ilmiah II Asosiasi Pengajar dan Peminat Hukum Berspektif Gender se Indonesia (APPHGI), pada 18-20 September 2006, di Surabaya. 